\title{
ANALISA FENOMENA KOROSI PELAT PIPA BAJA KARBON API 5L-X65 DALAM LARUTAN 7900 ML AIR LAUT DAN 100 ML AMONIAK PADA KONDISI GAS CO 2 DAN H2S JENUH PADA SUHU RUANG.
}

\author{
Nendi Suhendi Syafei ${ }^{1}$, Darmawan Hidayat ${ }^{2}$, Sri Suryaningsih ${ }^{3}$, Liu Kin Men ${ }^{4}$. \\ ${ }^{1,2,3)}$ Prodi Teknik Elektro, ${ }^{4)}$ Prodi Fisika, FMIPA Universitas Padjadjaran Bandung \\ ${ }^{1}$ n.suhendi@unpad.ac.id, 2Darmawan.hidayat@unpad.ac.id, \\ ${ }^{3}$ sri@phys.unpad.ac.id, ${ }^{4}$ Liu@phys.unpad.ac.id \\ DOI : 10.24036/eksakta/vol19-iss01/83
}

\begin{abstract}
Pada penelitian pipa baja karbon API 5L-X65 digunakan rumah sampel dengan spesimen tiga titik pembebanan berada lingkungan gas $\mathrm{CO}_{2}$ dan $\mathrm{H}_{2} \mathrm{~S}$ jenuh dalam larutan $4900 \mathrm{ml}$ air laut dan $100 \mathrm{ml}$ amoniak, maka akan terjadi peristiwa fenomena korosi yaitu korosi retak tegangan transgranular dan korosi retak tegangan intergranular berdasarkan hasil uji mikrostruktur dan mikroskop terpolarisasi. Dari hasil penelitian bahwa sampel uji dengan variasi bahwa laju korosi terhadap waktu paparan membentuk persamaan polynomial, dan dalamnya crack akan semakin dalam dengan semakin besar tegangan $\sigma$ yang diberikan pada sampel uji.
\end{abstract}

Keywords : korosi retak tegangan, spesimen tiga titik pembebanan, lingkungan.

\section{PENDAHULUAN.}

Penelitian laju korosi pada pipa baja karbon API 5L-Grade B pada di lingkungan gas $\mathrm{H}_{2} \mathrm{~S}$ kondisi $\mathrm{CO}_{2}$ jenuh dalam larutan $\mathrm{NaCl}$ (Nendi Suhendi Syafei,2014), laju korosi pada pipa baja karbon API 5L-Grade B di lingkungan gas $\mathrm{H}_{2} \mathrm{~S}$ dan kondisi $\mathrm{CO}_{2}$ jenuh dalam larutan $\mathrm{NaCl}$ dan larutan asam asetat (Nendi Suhendi Syafei, jurnal Fisika Indonesia no.55, Vol. XIX, edisi Nopember 2015, ISSN. 1410-2994), kajian korosi retak tegangan akibat sweet gas $\left(\mathrm{H}_{2} \mathrm{~S}\right.$ dan $\left.\mathrm{CO}_{2}\right)$ pada pipa baja karbon API 5L-X65 terhadap laju korosi dalam larutan asam asetat (Nendi Suhendi Syafei, 2016; Nendi Suhendi Syafei, Prosiding Semnas Inovasi dan Aplikasi Teknologi di Industri, Malang 4 februari 2017). Karakteristik Pipa Baja Karbon API 5L-X65 dengan Metoda Pembebanan Tiga Titik pada Lingkungan Gas $\mathrm{H}_{2} \mathrm{~S}$ Kondisi Jenuh $\mathrm{CO}_{2}$ dalam Larutan Asam
Asetat (Nendi Suhendi Syafei, Prosiding Seminar Nasionanl Energi dan Teknologi atau SINERGI 2017, Bekasi 9 Mei 2017). Analisis Pipa Baja Karbon API 5L-X65 dengan Metoda Pembebanan Tiga Titik pada Lingkungan $\mathrm{Gas} \mathrm{H}_{2} \mathrm{~S}$ Kondisi Jenuh $\mathrm{CO}_{2}$ dalam Larutan Asam Asetat (Nendi Suhendi Syafei, Seminar Nasional SENFA 2017, Balai Sawala Universitas Padjadjaran, 22 Juli 2017). Pengujian Kekerasan dan Uji Tarik Untuk Menentukan Koefisien Pengerasan $n$ Suatu Bahan API 5L-X65.( Nendi Suhendi Syafei, Darmawan Hidayat, Dessy Novita, Bernard Y Tumbelaka, Prosiding Pertemuan Ilmiah XXXI HFI Jateng \& DIY, Yogyakarta 18 Maret 2017 ISSN : 0853-0823). Analisa fenomena korosi pelat pipa baja karbon API 5L-X65 dalam larutan $250 \mathrm{ml}$ asam asetat dan 4750 aquades pada kondisi gas $\mathrm{CO}_{2}$ dan $\mathrm{H}_{2} \mathrm{~S}$ jenuh pada suhu ruang (Nendi Suhendi Syafei, Darmawan Hidayat, 
E-ISSN : 2549-7464, P-ISSN : 1411-3724

Bernard Y Tumbelaka, Liu Kin Men, Jurnal Eksakta Vol. 18 N0.2, Oktober 2017 halaman 113-120, E-ISSN : 25497464, P-ISSN : 1411-3724). Perbandingan Kajian Korosi Retak Tegangan Akibat Sweet Gas $\left(\mathrm{H}_{2} \mathrm{~S}\right.$ dan $\left.\mathrm{CO}_{2}\right)$ Pada Pipa Baja Karbon API 5L-X65 Terhadap Laju Korosi Dalam Larutan Asam AsetatAmoniak dengan Air Laut dan Dianalisis dengan Menggunakan Metoda Ultrasonik, Penelitian Riset Hibah Fundamental Unpad (RFU-HIU 2017, Nopember 2017, Universitas Padjadjaran). Dalam industri migas bila terjadi korosi retak regangan akan mengakibatkan fatal, yaitu pecahnya pipa sehingga akan mengakibatkan produksi migas akan terhenti.

Dari hasil penelitian pada pipa baja karbon API 5L-X60 yaitu $17 \mathrm{H}_{1} \mathrm{~S}$ akan rentan terhadap korosi retak tegangan. Dan sifat mekanik pipa baja karbon API 5L-X60 terdegradasi menunjukkan ketahanan yang lebih tinggi terhadap korosi retak tegangan dari pada pipa baja karbon. Berdasarkan hasil pengamatan dengan fraktografik bhawa pipa baja karbon akibat proses embrittlement hidrogen akan terjadi korosi retak tegangan, yaitu akibat disebabkan oleh atom hidrogen yang meresap kedalam pipa baja karbon (O. I. Zvirko , S. F. Savula, V. M. Tsependa , G. Gabetta, H. M. Nykyforchyn, 2016).

Ketahanan korosi yang tinggi pada pipa baja karbon tahan karat (super martensit) pada umumnya digunakan dalam industri minyak dan gas, yaitu terutama di lingkungan asam. Namun ada beberapa yang rentan dengan adanya hidrogen dan mekanisme proses korosi akan terjadi dengan adanya $\mathrm{H}_{2} \mathrm{~S}$ serta tergantung pada $\mathrm{pH} . \mathrm{H}_{2} \mathrm{~S}$ akan berdifusi merembes di sepanjang struktur logam maka akan terbentuk pori logam sulfida karena bereaksi pada permukaan logam, sehingga akan membebaskan hidrogen terikat dengan sulfur yang dapat diserapnya dan hidrogen yang ada dalam larutan $\mathrm{H}_{2} \mathrm{~S}$ secara tidak langsung menyebabkan kegagalan (Martin Monnota, Ricardo P. Nogueira, Virginie Roche, Grégory Berthomé, Eric Chauveau, Rafael Estevez, Marc Mantel, 2017).

Hal ini menyebabkan hilangnya sifat mekanik awal terutama ketahanan terhadap patah getas, yaitu berdasarkan perhitungan teknik pada tahap desain pipa. Pada waktu bersamaan korosi retak tegang telah diidentifikasi sebagai salah satu kegagalan dominan pada pipa baja karbon di lingkungan lembab, yaitu akan menyebabkan pecahnya pipa transmisi gas bertekanan tinggi serta kerugian ekonomi yang serius dan bencana.( O. I. Zvirko, S. F. Savula , V. M. Tsependa, G. Gabetta , H. M. Nykyforchyn, Procedia Structural Integrity 2 (2016) 509-516. 20-24 June 2016).

\section{METODE PENELITIAN}

Untuk membuat rumah sampel (holder) uji koros diperlukan lembaran baja berupa pelat atau flat extruded section yang berpenampang lintang persegi panjang, dan selain itu dapat juga digunakan besi cor atau besi dalam bentuk balok seperti terlihat pada gambar 1 . Bahan sampel uji korosi API 5L-X65 yang akan diuji ditipiskan dalam bentuk pelat tipis kemudian ditekuk pada kedua ujungnya sehingga mendapatkan tegangan, dan besarnya regangan dapat diatur dengan memberikan lendutan melalui skrup yang digerakkan dengan ulir seperti pada gambar (1.b) untuk menentukan defleksi y. Dan penelitian ini menggunakan sampel uji korosi berukuran panjang $12,5 \mathrm{~cm}$, lebar $2 \mathrm{~cm}$ dan tebalnya $2 \mathrm{~mm}$ (gambar 2) disimpan pada holder spesimen tiga titik pembebanan seperti pada gambar (1.a), gambar (1.b) rancangan bentuk holder dan 
sampel uji (gambar 2) ditekuk seperti pada gambar (1.c) dimasukkan kedalam ruang chamber uji korosi (gambar 3) dengan 2 variasi defleksi seperti pada gambar (1.c) (Nendi Suhendi Syafei, 2016).

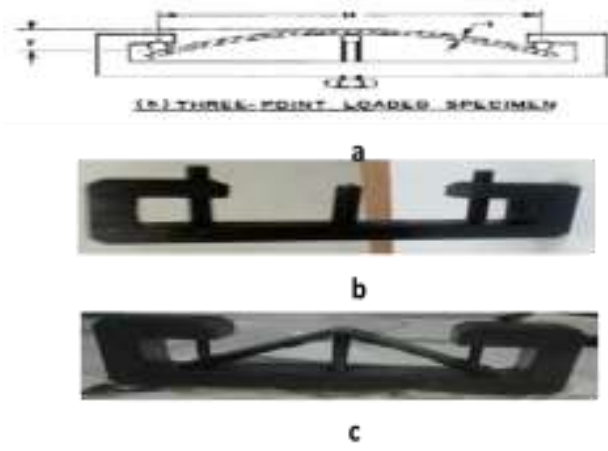

Gambar 1. Bentuk holder dan pemasangan spesimen uji.

Penelitian sampel uji korosi (seperti pada gambar 2) yang tersimpan dalam holder (gambar 1.c) diisi larutan asam asetat $250 \mathrm{ml}$ dan $4750 \mathrm{ml}$ aquades seperti ditunjukan pada gambar 3 . Populasi sampel uji korosi setiap variasi waktu terdiri dua buah sampel uji dengan 2 variasi defleksi, dan baik berat sampel uji sebelum diuji korosi dan berat sampel sesudah diuji korosi ditimbang beratnya.

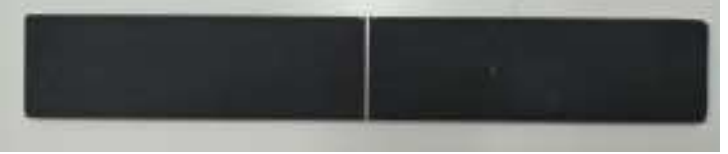

Gambar 2. Sampel uji korosi pelat API 5L-X65 diberi crack awalnya.
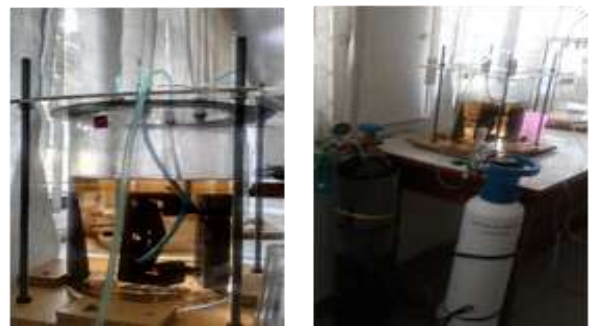

Gambar 3. Chamber uji korosi. (tabung berwarna putih berisi gas $\mathrm{H}_{2} \mathrm{~S}$ dan tabung berwarna hitam berisi $\mathrm{CO}_{2}$ ) pada suhu ruang..

Uji tarik adalah_uji stress-strain mekanik yang bertujuan untuk mengetahui kekuatan bahan terhadap gaya tarik. Dalam pengujiannya bahwa bahan uji ditarik sampai putus dan biasanya yang menjadi fokus adalah kemampuan maksimum bahan tersebut dalam menahan beban tarik, dan kemampuan/kekuatan tarik maksimum ini umumnya disebut "Ultimate Tensile Strength (UTS)". Perubahan panjang dalam kurva disebut sebagai regangan teknik (\&), yang didefinisikan sebagai perubahan panjang yang terjadi akibat perubahan statik $(\Delta \mathrm{L})$ terhadap panjang batang mula-mula $\left(\mathrm{L}_{0}\right)$.Tegangan yang dihasilkan pada proses ini disebut dengan tegangan teknik $(\boldsymbol{\sigma})$, dimana didefinisikan sebagai nilai pembebanan yang terjadi (F) pada suatu luas penampang awal (A) seperti gambar 4 . Tegangan normal tesebut akibat beban tekan statik dapat ditentukan berdasarkan persamaan berikut :

$\boldsymbol{\sigma}=\mathbf{F} / \mathbf{A o}$

dengan :

$\sigma=$ Tegangan normal akibat beban tarik statik $\left(\mathrm{N} / \mathrm{mm}^{2}\right)$,

$\mathrm{F}=$ Beban tarik $(\mathrm{N})$.

Ao $=$ Luas penampang spesimen mulamula $\left(\mathrm{mm}^{2}\right)$ seperti gambar 3 .

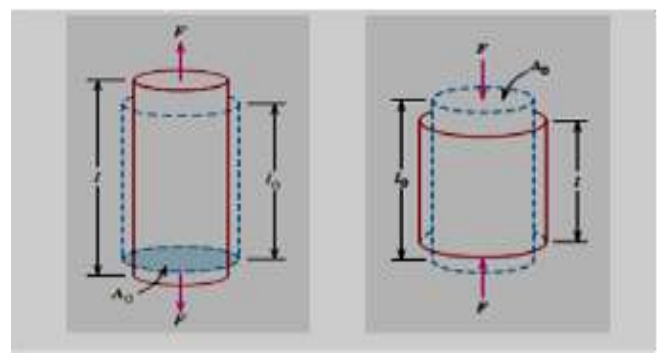

Gambar 4. Prinsip dasar tegangan/stress. (Callister, D. William 2007).

Regangan akibat beban tarik statik dapat ditentukan berdasarkan persamaan berikut : 
$\varepsilon=\Delta \mathbf{L} / \mathbf{L}$

dengan:

$\Delta \mathrm{L}=\mathrm{L}-\mathrm{L}_{0}, \boldsymbol{\varepsilon}=$ Regangan akibat beban tarik statik.

$\mathrm{L}=$ Perubahan panjang spesimen akibat beban tarik (mm).

Lo $=$ Panjang spesimen mula-mula $(\mathrm{mm})$.

Spesimen berbentuk keping datar mempunyai dimensi lebar, panjang, dan ketebalan spesimen biasanya ditentukan, dan penyangga spesimen sampel uji dikedua ujung ditahan kemudian ditekuk/ditekan dengan sekrup (dilengkapi dengan bola) dimana penyangga pendorong berada ditengah seperti pada gambar (1.a) dan (1.b). Dimensi spesimen sampel yang digunakan dapat dimodifikasi sesuai dengan kebutuhan, tetapi diperkirakan dimensinya secara proposional. Perhitungan regangan elastik seperti pada persamaan berikut :

$$
\sigma=6 \mathrm{E} \text { t } \mathbf{y} / \mathrm{H}^{2}
$$

dengan:

$\sigma=$ Tegangan tarik maksimum $\left(\mathrm{N} / \mathrm{m}^{2}\right)$.

$\mathrm{E}=$ modulus elastisitas $\left(\mathrm{N} / \mathrm{m}^{2}\right)$.

$\mathrm{t}=$ ketebalan spesimen $(\mathrm{mm})$

$\mathrm{y}=$ defleksi maksimum (mm).

$\mathrm{H}=$ jarak antara penyangga luar $(\mathrm{mm})$ dan defleksi kecil (y / H kurang dari 0,1) seperti ditunjukkan pada gambar (1.a). Spesimen keping datar dengan $25-51 \mathrm{~mm}$ (1-2 inci), panjang 127-254 mm (5 - 10 inci) dan ketebalan spesimen uji bahan yang digunakan seperti pada gambar 2 .

Data yang diperoleh berdasarkan berat sebelum dan sesudah diuji korosi dari sampel uji, yaitu untuk menghitung laju korosinya. Kemudian sampel uji tersebut diuji menggunakan mikrostruktur, yaitu untuk melihat pola struktur pelat baja karbon. Penelitian ini
E-ISSN : 2549-7464, P-ISSN : 1411-3724

perlu dikembangkan dengan menggunakan metoda ultrasonik untuk mengetahui panjang crack yaitu berdasarkan pantulan gelombang yang mengenai permukaan plat baja karbon.

Sampel pelat baja karbon API 5LX65 pada holder dimasukkan kedalam ruang chamber uji korosi, kemudian diisikan gas $\mathrm{CO}_{2}$ hingga kondisi jenuh lalu diisikan gas $\mathrm{H}_{2} \mathrm{~S}$ selama 10 menit. Data perhitungan laju korosi sampel uji dalam ruang chamber diisi gas $\mathrm{H}_{2} \mathrm{~S}$ selama 10 menit dengan variasi waktu paparan 720 jam, 1080 jam, 1440 jam dengan defleksi $0,5 \mathrm{~cm}, 1,0 \mathrm{~cm} 1,5 \mathrm{~cm}$ seperti pada tabel 1 dan data perhitungan regangan $\boldsymbol{\sigma}$ seperti pada tabel 2. Tabel 3 data grafik laju korosi terhadap dalamnya crack, dan tabel 4 data grafik dalamnya crack terhadap regangan menggunakan persamaan (3) diperoleh seperti pada tabel 1 .

\section{HASIL PENELITIAN DAN PEMBAHASAN}

\section{Hasil Penelitian.}

Tabel 1. Data perhitungan laju korosi sampel uji.

\begin{tabular}{|c|c|c|c|c|c|c|c|c|c|}
\hline & $\begin{array}{l}\text { M } \\
\text { awal } \\
\text { (gr) }\end{array}$ & $\begin{array}{l}\text { M } \\
\text { akhir } \\
\text { (gr) }\end{array}$ & $\begin{array}{l}\text { PH } \\
\text { awal }\end{array}$ & $\begin{array}{l}\text { PH } \\
\text { l akhir }\end{array}$ & $\begin{array}{l}\text { Panjang } \\
\mathbf{r}(\mathrm{cm})\end{array}$ & $\begin{array}{l}\text { Lebar } \\
(\mathrm{cm})\end{array}$ & $\begin{array}{l}\text { Tebal } \\
(\mathrm{cm})\end{array}$ & $\begin{array}{l}\text { Waktu } \\
\text { Paparan } \\
\text { (Jam) }\end{array}$ & $\begin{array}{l}\text { Laju Korosi } \\
\text { (mmpy) }\end{array}$ \\
\hline & 52.99 & 52.96 & 14 & 10 & 13.1 & 2.42 & 2.4 & 336 & 0.031388956 \\
\hline & 53.73 & 53.53 & 14 & 10 & 13.1 & 2.42 & 2.4 & 336 & 0.209259709 \\
\hline & 53.18 & 52.69 & 14 & 10 & 13.1 & 2.42 & 2.4 & 336 & 0.512686287 \\
\hline & 53.21 & 52.76 & 14 & & 13.1 & 2.42 & 2.4 & 672 & 0.235417172 \\
\hline & 53.29 & 52.65 & 14 & & 13.1 & 2.42 & 2.4 & 672 & 0.334815534 \\
\hline & $\mathbf{5 3 . 9 6}$ & 52.76 & 14 & & 13.1 & 2.42 & 2.4 & 672 & 0.627779127 \\
\hline & 53.33 & 52.95 & 14 & & 13.1 & 2.42 & 2.4 & 1008 & 0.132531149 \\
\hline & 53.13 & 52.7 & 14 & & 13.1 & 2.42 & 2.4 & 1008 & 0.149969458 \\
\hline & 53.26 & & 14 & 9 & 13.1 & 2.42 & 2.4 & 1008 & 0.219722694 \\
\hline
\end{tabular}

Tabel 2. Data perhitungan tegangan $\boldsymbol{\sigma}$.

\begin{tabular}{|c|c|c|c|c|c|c|}
\hline No & $E\left(N / m^{2}\right)$ & $\mathbf{t}(\mathbf{m})$ & $\mathbf{y}(\mathbf{m})$ & $\mathbf{H}(\mathbf{m})$ & $\mathbf{H}^{2}\left(\mathrm{~m}^{2}\right)$ & $\sigma\left(\mathrm{N} / \mathrm{m}^{2}\right)$ \\
\hline 1 & $2.05 E+11$ & 0.0022 & 0.005 & 0.0946 & 0.00894916 & 1511873740 \\
\hline 2 & $2.05 E+11$ & 0.0022 & 0.01 & 0.0946 & 0.00894916 & 3023747480 \\
\hline 3 & $2.05 E+11$ & 0.0022 & 0.015 & 0.0946 & 0.00894916 & 4535621220 \\
\hline
\end{tabular}


E-ISSN : 2549-7464, P-ISSN : 1411-3724

Tabel 3. Data grafik laju korosi terhadap waktu paparan dengan defleksi yang sama.

\begin{tabular}{|c|c|c|c|}
\hline No. & $\begin{array}{l}\text { Defleksi } \\
\text { (cm) }\end{array}$ & $\begin{array}{l}\text { Laju Korosi } \\
\text { (mmpy) }\end{array}$ & $\begin{array}{l}\text { Waktu } \\
\text { Paparan (jam) }\end{array}$ \\
\hline 1 & 0.5 & 0.031388956 & 336 \\
\hline 2 & 0.5 & 0.235417172 & 672 \\
\hline 3 & 0.5 & 0.132531149 & 1008 \\
\hline 4 & 1 & 0.209259709 & 336 \\
\hline 5 & 1 & 0.334815534 & 672 \\
\hline 6 & 1 & 0.149969458 & 1008 \\
\hline 7 & 1.5 & 0.512686287 & 336 \\
\hline 8 & 1.5 & 0.627779127 & 672 \\
\hline 9 & 1.5 & 0.219722694 & 1008 \\
\hline
\end{tabular}

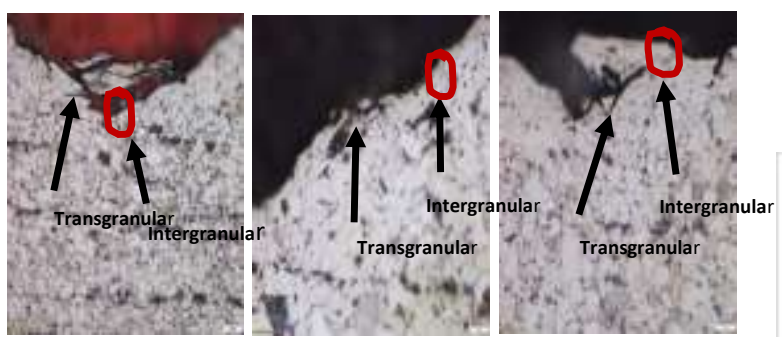
(a) C3.
(b) A1.
(c) B1.

Gambar 5. Hasil mikrostruktur terjadi korosi retak tegangan transgranular dan intergranular (garis merah), (a) sampel C3, (b) sampel A1 dan (c) sampel B1.

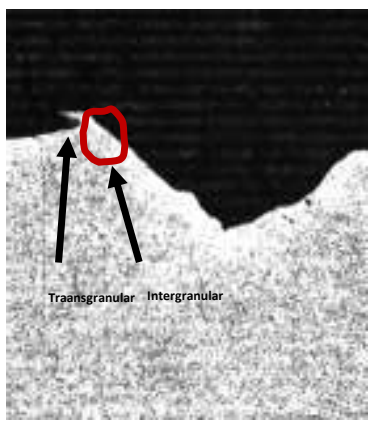

(a) B3.

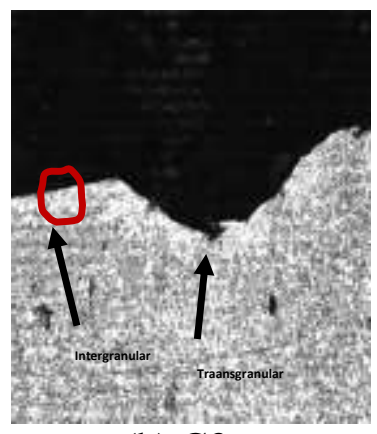

(b) C3.
Gambar 6. Hasil mikroskop terpolarisasi terjadi korosi retak tegangan transgranular dan intergranular (garis merah), (a) sampel B3 dan (b) sampel C3.

Grafik laju korosi terhadap waktu paparan dengan defleksi yang sama berdasarkan tabel 3 ditunjukkan pada gambar 6. Dan grafik dalamnya crack terhadap defleksi y berdasarkan tabel 4 ditunjukkan pada gambar 7 .

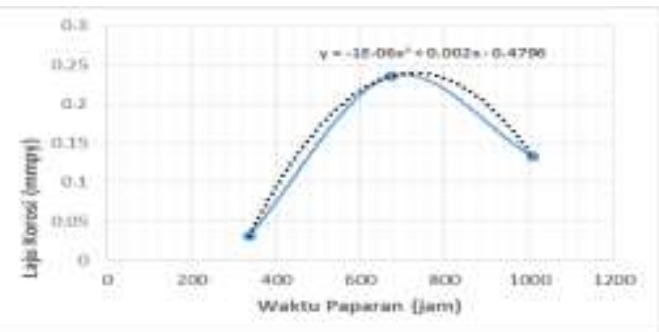

(1) Defleksi 0,5 cm.

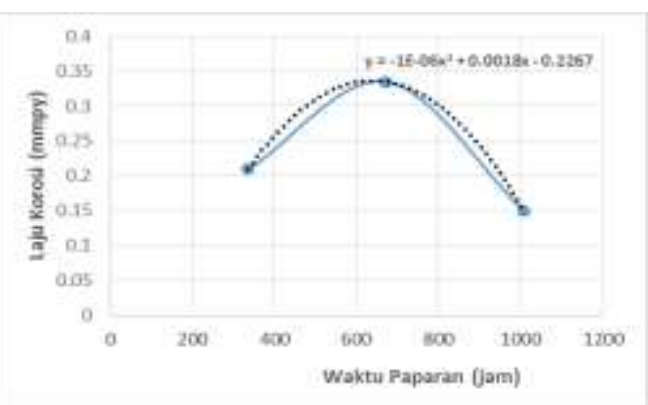

(2) Defleksi $1,0 \mathrm{~cm}$.

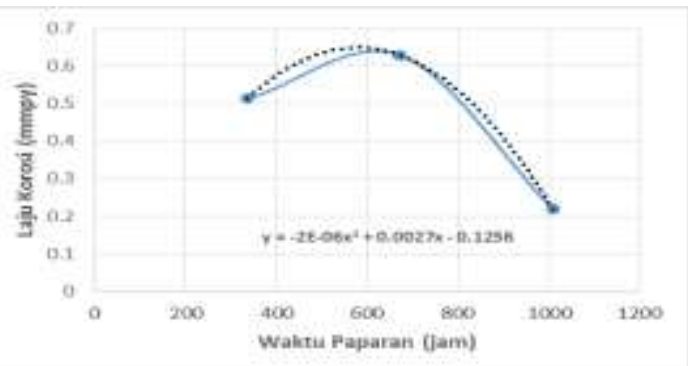

(3) Defleksi $1,5 \mathrm{~cm}$.

Gambar 6. Grafik laju korosi (mmpy) terhadap waktu paparan (jam) dengan defleksi yang sama.

Tabel 4. Data grafik dalamnya crack $(\mu \mathrm{m})$ terhadap regangan $\boldsymbol{\sigma}$ dengan defleksi yang sama.

\begin{tabular}{|r|r|r|}
\hline No. & \multicolumn{2}{|c|}{$\begin{array}{l}\text { Dalamnya Crack } \\
(\boldsymbol{\mu m})\end{array}$} \\
\hline 1 & 1511873740 & 62.36 \\
\hline 3023747480 & 76.76 \\
\hline 2 & 1511873740 & 79.89 \\
\hline 3023747480 & 66.98 \\
\hline 3 & 1535621220 & 69.93 \\
\hline & 3023747480 & 89.86 \\
\hline 4535621220 & 65.32 \\
\hline & 90.79 \\
\hline
\end{tabular}


Berdasarkan

mikrostruktur seperti pada gambar 4 dan berdasarkan mikroskop terpolarisasi seperti pada gambar 6 bahwa terjadi fernomena korosi retak tegangan transgranular dan intergranular.

\section{KESIMPULAN}

Bahwa sampel uji dari pelat baja karbon API 5L-X65 berada dalam larutan 4900 $\mathrm{ml}$ air laut dan $100 \mathrm{ml}$ amoniak dalam kondisi gas $\mathrm{CO}_{2}$ dan $\mathrm{H}_{2} \mathrm{~S}$ jenuh, berdasarkan hasil uji mikrostruktur terjadi peristiwa korosi retak tegangan transgranular dan intergranular.

Laju korosi terhadap variasi waktu paparan untuk defleksi yang sama seperti pada gambar 6 membentuk persamaan

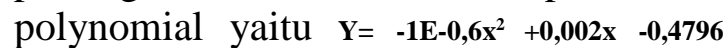
untuk defleksi $0,5 \mathrm{~cm}, \mathbf{Y}=-\mathbf{1 E}-\mathbf{0}, \mathbf{6} \mathbf{x}^{2}+\mathbf{0 , 0 0 1 8}$ $\mathbf{0 , 2 2 6 7}$ untuk defleksi $1,0 \mathrm{~cm}$ dan $\mathbf{Y}=-\mathbf{2 E}-\mathbf{0 , 6} \mathbf{6} \mathbf{x}^{2}+$ $\mathbf{0 , 0 0 2 7} \mathbf{x}+\mathbf{0 , 1 2 5 6}$ untuk defleksi $1,5 \mathrm{~cm}$ (Y adalah laju korosi dan $\mathrm{x}$ adalah waktu paparan).

Dalamnya crack akan semakin dalam dengan tegangan $\boldsymbol{\sigma}$ semakin besar yang diberikan pada sampel uji seperti pada gambar 7 membentuk persamaan polynomial yaitu $\mathbf{Y}=-\mathbf{2 E}-18 \mathrm{x}^{2}+\mathbf{2 E - 0 8} \mathrm{x}+\mathbf{3 6 , 6 9}$ untuk waktu paparan 336 jam, $\mathbf{Y}=\mathbf{4 E - 1 8} \mathbf{x}^{2}$ 1E-08x $+\mathbf{8 1 , 0 1}$ untuk waktu paparan 672 jam

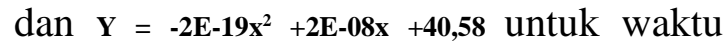
paparan 1008 jam (Y adalah dalamnya crack dan $\mathrm{x}$ adalah regangan $\boldsymbol{\sigma}$ ).

\section{DAFTAR PUSTAKA}

Nendi Suhendi-Sri Suryaningsih-Otong Nurhilal. (Nopember 2014), "Kajian Korosi Retak Tegangan akibat sweet gas $\left(\mathrm{H}_{2} \mathrm{~S}\right.$ dan $\left.\mathrm{CO}_{2}\right)$ pada Pipa Baja Karbon", FMIPA Universitas Padjadjaran.

Nendi Suhendi Syafei, Sri Suyaningsih, Otong Nurhilal, Febi Luthfiani.(Ed. Nov 2015), "Analisa Regangan (Stress) Pada Pipa Baja Karbon API 5L GradeB Terhadap Laju Korosi Dalam Larutan $\mathrm{NaCl}$ dan Asam 
Asetat". Jurnal Fisika Indonesia No. 56 Vol. XIX ISSN 1410-2994.

Nendi Suhendi Syafei-Zaida-Liu Kin Men.(Desember 2016). "Kajian Korosi Retak Tegangan akibat sweet gas (H2S dan $\mathrm{CO} 2$ ) pada pipa baa karbon API 5L-X65 terhadap Laju Korosi dalam Larutan Asam Asetat dan Dianalisis dengan Metoda Ultrasonik", Program Studi Teknik elektro FMIPA Universitas Padjadjaran.

Nendi Suhendi Syafei - Darmawan Hidayat - Bernard Y Tumbelaka Zaida - Liu Kin Men. (4 Februari 2017), "Analisa Laju Korosi pada Pipa Baja Karbon API 5L-X65 dengan Metoda Pembebanan Tiga Titik pada Lingkungan Gas H2S Kondisi Jenuh $\mathrm{CO} 2$ dalam Larutan Asam Asetat", Prosiding Seminar Nasional Inovasi Dan Aplikasi Teknologi Di Industri, ITN Malang, hal. D12.1-D12.5, ISSN 2085-4218.

Nendi Suhendi Syafei, Darmawan Hidayat, Dessy Novita, Bernard Y Tumbelaka, Pengujian Kekerasan dan Uji Tarik Untuk Menentukan Koefisien Pengerasan $n$ Suatu Bahan API 5L-X65, Prosiding Pertemuan Ilmiah XXXI HFI Jateng \& DIY, Yogyakarta 18 Maret 2017 ISSN : 0853-0823.

Nendi Suhendi Syafei-Darmawan Hidayat-Bernard Y TumbelakaMuhammad taufik. (9 mei 2017), "Karakteristik Pipa Baja Karbon API 5L-X65 dengan Metoda Pembebanan Tiga Titik pada Lingkungan Gas H2S Kondisi Jenuh CO2 dalam Larutan Asam Asetat", Prosiding Seminar Nasional Energi dan Teknologi
(Seinergi) Unisma Bekasi, hal.3339, ISSN:2527-3108.

Nendi Suhendi Syafei-Darmawan Hidayat-Bernard Y Tumbelaka-Liu Kin Men, Analisa fenomena korosi pelat pipa baja karbon API 5L-X65 dalam larutan $250 \mathrm{ml}$ asam asetat dan 4750 aquades pada kondisi gas $\mathrm{CO} 2$ dan $\mathrm{H} 2 \mathrm{~S}$ jenuh pada suhu ruang, Eksakta Vol. 18 N0.2, Oktober 2017, halaman 113120,E-ISSN:2549-7464, P-ISSN : 1411-3724.

Nendi Suhendi Syafei,-Liu Kin Men, Perbandingan Kajian Korosi Retak Tegangan Akibat Sweet Gas (H2S dan CO2 ) Pada Pipa Baja Karbon API 5L-X65 Terhadap Laju Korosi Dalam Larutan Asam AsetatAmoniak dengan Air Laut dan Dianalisis dengan Menggunakan Metoda Ultrasonik, Penelitian Riset Hibah Unpad (RFU-HIU 2107, Universitas Padjadjaran).

O. I. Zvirko , S. F. Savula , V. M. Tsependa , G. Gabetta , H. M. Nykyforchyn. (2016), "Stress corrosion cracking of gas pipeline steels of different strength", 21st European Conference on Fracture, ECF21, 20-24 June 2016, Catania, Italy. Procedia Structural Integrity 2 509-516.

Martin Monnota, Ricardo P. Nogueira, Virginie Roche, Grégory Berthomé, Eric Chauveau, Rafael Estevez, Marc Mantel.(2017). "Sulfide stress corrosion study of a super martensitic stainless steel in $\mathrm{H} 2 \mathrm{~S}$ sour environments: Metallic sulfides formation and hydrogen embrittlement", Applied Surface Science 394 132-141. 